\title{
Desenvolvimento docente para educação remota emergencial em 2020: a experiência da Faculdade de Medicina de Ribeirão Preto da Universidade de São Paulo (FMRP-USP)
}

\author{
Faculty Development for Emergency Remote Education in 2020: the \\ experience at Ribeirão Preto School of Medicine, University of São Paulo \\ (FMRP-USP)
}

Fabio Carmona ${ }^{1}$ (D), Valdes Roberto Bollela² (D)

\begin{abstract}
RESUMO:
Após a suspensão das aulas presenciais em 2020, devido à pandemia da Covid-19, foi necessário viabilizar educação remota emergencial para milhares de estudantes de todos os níveis do ensino no Brasil. Quase ninguém estava preparado para enfrentar um desafio desta grandeza. Por conta da falta de familiaridade com as estratégias de educação mediada por tecnologia, única modalidade de ensino disponível naquele momento, essa situação logo trouxe à tona sinais de fadiga e estresse entre professores e estudantes. Era perceptível também a necessidade, por parte dos professores, de treinamento para apropriarem-se dos recursos existentes na universidade para a educação remota. A energia dispendida para preparação das aulas, atividades e avaliações no contexto da educação remota era enorme e seria necessário adquirir competências básicas para manter os processos de ensino-aprendizagem e avaliação dos estudantes acontecendo e com boa qualidade. Estes sinais e pedidos de ajuda, por parte dos professores e estudantes, começam a ficar evidentes no final de maio de 2020 na Faculdade de Medicina de Ribeirão Preto da Universidade de São Paulo (FMRP-USP). Estudantes reclamavam de sobrecarga de conteúdo, sobreposição e desorganização das atividades propostas para o ambiente virtual e estavam muito ansiosos com a avaliação que teriam ao final do semestre. Por outro lado, víamos professores inseguros para oferecerem atividades online, ou em dúvida sobre como cuidar de vários aspectos, tais como registro de frequência, participação ativa nas aulas, e, principalmente, avaliação do estudante. Enfim, como utilizar recursos de educação remota, partindo de pouca ou quase nenhuma experiência prévia? Neste contexto, o Centro de Desenvolvimento Docente para o Ensino (CDDE) da FMRP-USP identifica as necessidades dos docentes e propõe um treinamento voltado para a plataforma e-Disciplinas da USP, assegurando os princípios básicos de boa educação e avaliação dos estudantes. Daí nasce o módulo básico de educação remota para profissões da saúde, que busca atender docentes com diferentes necessidades na FMRP-USP. Para aqueles professores com maior expertise em educação a distância, realizamos dois cursos completos empregando o ensino híbrido a partir da estratégia da sala de aula invertida, mas de maneira remota (remote flipped classroom). Para um público mais iniciante ou que não teria condições de se dedicar ao curso completo, disponibilizamos ajuda personalizada. Esta é a experiência que apresentamos neste artigo e que servirá de base para adequações necessárias para o enfrentamento do desafio da educação durante e após a fase mais aguda da pandemia da Covid-19.
\end{abstract}

Palavras-chave: Educação à distância; Aprendizagem online; Teleducação; Escolas para Profissionais de Saúde; Covid-19

\footnotetext{
ABSTRACT:

After the suspension of face-to-face classes in 2020, due to the Covid-19 pandemic, it was necessary to provide emergency remote education for thousands of students at all levels of education in Brazil. No one was prepared
}

MD, PhD - Universidade de São Paulo, Faculdade de Medicina de Ribeirão Preto, Departamento de Puericultura e Pediatria, São Paulo, Brasil ; MD, PhD - Universidade de São Paulo, Faculdade de Medicina de Ribeirão Preto, Departamento de Clínica Médica, São Paulo, Brasil. 
to face such a challenge. Due to the lack of familiarity with technology-mediated education strategies, the only available at that, this situation soon brought to light signs of fatigue and stress among teachers and students. It was also noticeable the need, on the part of teachers, of training to take advantage of the existing resources for remote education at the university. The energy expended for the preparation of classes, activities, and assessments in the context of remote education was enormous and it would be necessary to acquire basic skills to keep the teaching-learning and assessment processes of students happening and with good quality. These signs and requests for help on the part of teachers and students began to become evident at the end of May 2020 at the Ribeirão Preto Medical School of the University of São Paulo (FMRP-USP). Students complained about content overload, overlapping and disorganization of the activities proposed for the virtual environment, and were very anxious about the assessments they would have at the end of the semester. On the other hand, we saw insecure teachers offering online activities, unsure of how to take care of various aspects, such as: recording attendance, engaging students in online classes and, most importantly, student assessment. In short, how to use remote education resources, starting from little or almost no previous experience? In this context, the Center of Faculty Development for Teaching (CDDE) of FMRP-USP assesses the needs of teachers and proposes a training focused on the use of the USP e-Disciplines platform, according to the basic principles of good education and student assessment. For those teachers with greater expertise in remote education, we conducted two complete courses using hybrid teaching based on the remote flipped classroom strategy. For a more novice audience or for those who would not be able to dedicate themselves to the complete course, we provided personalized help. This is the experience that we present in this article and that will serve as a basis for the necessary adaptations to face the education challenge during and after the most acute phase of the Covid-19 pandemic.

keywords: Education, distance; Online, Learning; teleducation; Schools, health occupations; Covid-19

\section{MENSAGENS PRINCIPAIS:}

- A pandemia da Covid-19 desestruturou o ensino em todo o mundo. Os cursos da área da saúde sofreram e continuam com o desafio de manter atividades remotas de boa qualidade para não haver solução de continuidade na formação dos profissionais essenciais no combate da emergência sanitária global;
- $\quad$ Professores e estudantes não estavam preparados para manter atividades educacionais quase que exclusivamente através de estratégias de educação remota ou a distância (EaD);

- Os sinais de estresse e pedidos de ajuda mobilizaram aqueles que tinham mais experiência com a EaD e estas pessoas, com apoio de instâncias voltadas para capacitação docente, traçaram e executaram um plano de contingência para as lacunas detectadas e que pudessem promover capacitação docente para a educação remota emergencial;

- O curso de capacitação, mais do que criar competência, criou uma rede de suporte e ajuda para os professores da FMRP-USP.

\section{INTRODUÇÃO:}

Quando se iniciou o ano letivo de 2020, já se ouviam as notícias sobre a nova doença, inicialmente descrita no final de 2019 na China, que era causada por um novo coronavírus (SARSCoV-2), que ficou conhecida por COVID-19. A rápida disseminação da doença pelo mundo levou a Organização Mundial da Saúde (OMS) a decretar emergência mundial em 30 de janeiro de $2020^{1}$, mas foi somente em 11 de março de 2020 que a OMS elevou a COVID-19 à condição de pande$\mathrm{mia}^{2}$. No Brasil, o primeiro caso foi confirmado em 26 de fevereiro de $2020^{1}$ e, desde então, medidas de higiene e isolamento social têm sido fortemente enfatizadas. Em 24 de março de 2020 teve início a quarentena em todo o estado de São Paulo ${ }^{3}$, impactando significativamente todas as atividades humanas, incluindo a educação, em todos os seus níveis. Na Universidade de São Paulo, todas as aulas presenciais foram suspensas logo em seguida, exceto os estágios profissionalizantes da área da saúde. A Universidade de São Paulo (USP) recomendou às unidades e respectivos docentes que todas as atividades didáticas deveriam continuar sendo oferecidas, dentro do possível, de forma remota, via Internet. Esperava-se que as atividades práticas seriam repostas assim que a situação epidemiológica permitisse. 
Neste cenário, estudantes e professores se viram diante do desafio de utilizar recursos de educação remota, partindo de pouca ou quase nenhuma experiência prévia fazendo isso de maneira predominante em sua prática docente. Soma-se a esta situação o fato de todos terem sido afetados, de alguma forma no que diz respeito a saúde mental e as relações sociais que foram profundamente comprometidas pelo isolamento social. Se isso não bastasse, muitas pessoas (especialmente os estudantes) tiveram sérias dificuldades no momento inicial com conexões de Internet limitadas e falta ou precariedade de equipamentos necessários ao ensino remoto exclusivo.

No início da pandemia a USP já contava com um ambiente virtual de aprendizagem (AVA) que servia de apoio aos docentes e estudantes há vários anos, o e-Disciplinas (https://edisciplinas.usp.br), que é uma instância customizada da plataforma Moodle (https://moodle.org) que tem uma qualidade muito boa e com inúmeras funcionalidades disponíveis para educação a distância (EaD). No primeiro semestre de 2020, a USP e a Faculdade de Medicina de Ribeirão Preto (FMRP) ofereceram suporte à comunidade, incluindo empréstimo de equipamentos e acesso à Internet para as pessoas que manifestaram interesse e necessidade. Entretanto, ainda faltava a expertise para a educação remota para a maioria dos docentes e familiaridade para esta modalidade de ensino a maioria dos discentes. Neste momento, a comunidade acadêmica foi se ajustando ao que estava sendo possível realizar e a maioria das atividades aconteceram com um alto grau de improvisação. Resumindo, a comunidade acadêmica buscava sobreviver ao impacto inicial da pandemia. Ao final do primeiro semestre, alguns professores da FMRP-USP verbalizaram que estavam muito sobrecarregados, ainda perdidos e se sentindo "abandonados".

Segundo o relatório da McKinsey \& Company ${ }^{4}$, intitulado "Getting the next phase of remote learning right in higher education", algumas medidas precisavam ser adotadas nas instituições de ensino superior, e dentre as recomendações destacamos: (1) focar em acesso e equidade; (2) apoiar os professores; (3) Colocar o time todo online; (4) acionar as lideranças; e (5) investir em segurança digital. Desde o final de 2016, a FMRP conta com um Centro de Desenvolvimento Docente para o Ensino (CDDE), cuja meta é "ajudar professores/educadores a desenvolverem habilidades relevantes para a sua instituição e adequadas à sua posição e às responsabilidades, além de auxiliá-los a manter e sustentar a sua vitalidade enquanto educadores no presente e no futuro". Os membros do do CDDE são docentes da instituição e que também foram atingidos pelo tsunami da pandemia Covid-19, mas também tinham a obrigação de propor e implementar ações e atividades que pudessem dar apoio e suporte aos docentes que estavam em dificuldade com os desafios da educação remota emergencial. E assim, no final de junho conseguimos desenhar e oferecer treinamento para o corpo docente focando na educação remota.

O objetivo deste artigo é relatar essa experiência na FMRP-USP de oferecer desenvolvimento docente através de um curso intitulado "e-Módulo Básico (e-MB): Educação remota para as profissões da saúde. Desde 2016, o CDDE já oferecia cursos de capacitação docente na FMRP-USP. O carro-chefe das oficinas e cursos era o "Módulo Básico de Educação nas profissões da saúde" (MB -EPS) que tinha duração de cinco semanas e 40 hs de atividades ( 20 horas presenciais e 20 horas em atividades a distância dentro do e-Disciplinas da USP). Ao final, cada docente participante deveria elaborar uma proposta de intervenção na disciplina ou estágio que atua ensinando na FMRP-USP. O MB-EPS já utilizava educação híbrida (presencial e EaD) focando nos seguintes temas: princípios de aprendizagem de adultos, ambiente educacional, desenho curricular, estratégias de ensino e aprendizagem, avaliação do estudante, gestão e planejamento educacional, avaliação de programas educacionais. Até o início de 2020, o CDDE já havia oferecido o MB-EPS cinco vezes e em junho de 2020 começamos a desenhar, a partir da nossa experiência prévia, um módulo básico de educação remota emergencial para professores da FMRP-USP, o que chamamos de e-MB, ou módulo básico sobre educação remota emergencial.

O conteúdo e temas abordados no e-MB foram definidos a partir de um questionário enviado aos docentes em maio de 2020, que identificou e 
caracterizou as necessidades dos docentes logo após os primeiros três meses da pandemia. O questionário foi enviado a 315 docentes dos setes cursos da FMRP-USP e tivemos $166(52,7 \%)$ respostas que indicaram $90,5 \%$ tinham interesse em participar de cursos e treinamentos sobre educação mediada por tecnologias; $54,2 \%$ concordaram em participar dos cursos já nas férias do mês de julho (entre o primeiro e segundo semestre), $31,9 \%$ concordaram em participar de cursos nas férias e também no segundo semestre de 2020; $13,9 \%$ se mostraram interesse em participar de oficinas de capacitação docente no segundo semestre. Os principais temas mencionados entre as necessidades pelos docentes foram: aprender mais sobre recursos do e-Disciplinas da USP, aulas síncronas usando o Google Meet ou o M-Conf, avaliação do estudante online, aulas interativas on-line, entre outros temas.

Toda a organização e o desenvolvimento do e-MB de educação remota para profissões da saúde foi baseado na metodologia ADDIE, um acrônimo para: analysis, design, development, implementation, and evaluation ${ }^{5}$, que será detalhada em outro artigo deste simpósio que dará mais ênfase a aspectos ligados ao desenho instrucional de atividades voltadas à EaD. A seguir explicamos passo a passo o que foi feito.

\section{ANALYSIS (ANÁLISE)}

A análise de necessidades foi feita a partir da experiência dos docentes do CDDE que também estavam enfrentando o desafio da transição do modelo de ensino presencial para um formato $100 \%$ oferecido através da educação remota emergencial. Além disso, elaboramos o questionário que foi mencionado acima para guiar o núcleo docente do CDDE e priorizar temas relevantes para a maioria dos docentes da FMRP-USP. Após a análise dos questionários ficou muito claro que a maioria dos docentes precisava de aprender mais sobre os recursos do e-Disciplinas, a plataforma de EaD que a USP já disponibilizava aos seus docentes, mas que até 2020, ainda era usada de maneira pontual e periférica na maioria dos cursos de graduação. Apesar de ser composto por docentes experientes e com uma base sólida em vários aspectos ligados a educação nas profissões da saúde, logo percebemos que nem todos os membros do CDDE tinham familiaridade com EaD, educação remota ou mesmo com o e-Disciplinas que seria o tema central da capacitação docente que seria oferecida. Para fazer frente a este desafio fizemos uma prospecção, dentro da própria Faculdade, para identificar pessoas (docentes ou funcionários técnicos administrativos) que seriam a base do nosso corpo docente, com expertise no tema que seria ensinado. Felizmente, recursos humanos com estas características foram identificados dentro e fora do CDDE e prontamente se colocaram à disposição da equipe do CDDE para ajudar.

\section{DESIGN (DELINEAMENTO)}

A partir das percepções dos docentes que responderam à enquete e da experiência dos membros do CDDE, foi proposta a criação de um curso intitulado "e-Módulo Básico (e-MB): Educação Mediada por Tecnologias nas Profissões da Saúde". O eixo central do curso estava em torno do uso do e-Disciplinas para Educação Remota emergencial e para a EaD. Como o perfil do público-alvo era bastante diverso, docentes que nunca usaram o e-Disciplinas (iniciantes), docentes com alguma experiência (nível intermediário) e docentes com bastante experiência (avançados) foram planejadas três estratégias educacionais diferentes, resultando em três cursos, visando atingir os três públicos. Além disso, consideramos a possibilidade de que alguns docentes talvez não pudessem participar dos cursos de capacitação devido a falta de disponibilidade de tempo ou porque não tinham interesse em tudo o que seria abordado, e teriam interesses mais direcionados para alguma demanda específica. Para este quarto grupo, pensamos em disponibilizar um curso no formato estudo dirigido, em que o docente realiza apenas o módulo que lhe interessa, assistindo vídeos gravados e com exemplos de como utilizar os recursos do e-Disciplinas. para este grupo também era oferecido um grupo de apoio (help-desk) caso ainda persistisse alguma dúvida.

Para fazer a inscrição nos três formatos do e-MB que foram oferecidos pelo CDDE, o docente deveria responder a algumas perguntas que auto- 
maticamente o classificavam como sendo uma pessoa de nível mais iniciante, intermediário ou avançado, e o direcionava para o curso mais compatível com suas necessidades e conhecimentos prévios.

Para os docentes que não tinham interesse em fazer um treinamento completo ou para aqueles que tinham interesse em temas específicos e se sentiam seguros para aprender de maneira solo, deixamos disponível o "e-MB Estudo Dirigido", em que cada aluno escolhe o que precisa e cumpre o seu módulo sem a participação direta de um facilitador do CDDE.

A seguir descrevemos de maneira breve estes diferentes formatos de treinamento que foram propostos e executados ao longo de 2020, a partir do final de junho. Apresentaremos inicialmente o e-MB intermediário que é o mais completo e aquele que tinha a maior demanda. A seguir comentamos sobre o e-MB para iniciantes, pessoas com mais experiência com EaD e o e-MB estudo Dirigido.

\section{E-MÓDULO BÁSICO (INTERMEDIÁ- RIO) OU E-MB.INT}

Esta estratégia foi planejada para o docente que já tivesse alguma familiaridade com ambientes virtuais de aprendizagem (AVAs) ou a plataforma Moodle/eDisciplinas, e que tivesse disponibilidade para participação em atividades no calendário proposto em oito encontros síncronas de duas horas cada uma. Além disso, o participante teria de cumprir atividades assíncronas e também desenvolver um ambiente de ensino no e-Disciplinas ou revisar/ampliar/melhorar algum que já tivesse sido criado para suas disciplinas previamente. 0 trabalho neste ambiente constituiria o trabalho de conclusão de cursos de cada participante. Assim cada um aprenderia sobre os recursos disponíveis no e-Disciplinas e teria a oportunidade de aplicar o que aprendeu. Por exemplo, criar uma lista de presença, ou um questionário com testes de múltipla escolha que seriam respondidos pelos seus alunos antes de uma atividade síncrona. Tudo o que fosse desenvolvido no ambiente virtual teste do participante serviria para que os colegas (pares) pudessem testar e dar devolutiva, e também para que os facilitadores pudessem avaliar o pro- gresso e aprendizado sobre cada um dos temas que estavam sendo abordados.

O curso e-MB.int foi planejado no formato sala de aula invertida remota (remote flipped classroom) com oito módulos, que ocorreriam duas vezes por semana, com duração total de quatro semanas de curso e carga horária de 40 horas (Quadro 1). Os demais cursos (e-MB. ini e e-MB.ed) foram adaptados a partir deste. No total foram oito módulos e todos tinham a mesma estrutura com os módulos seguintes elementos:

- Momento do Preparo pré encontro síncrono - consistiu em atividades (assíncronas) que deveriam ser completadas antes do encontro propriamente dito, tais como leitura de textos selecionados e vídeos demonstrativos.

- Momento síncrono - Encontro de todos - consistiu em webconferências (síncronas) com 60 (na $1^{a}$ edição) ou 90 (na $2^{a}$ edição) minutos de duração, incluindo revisão do módulo anterior, breve apresentação oral sobre o assunto do dia, discussão e explicação sobre a tarefa a ser realizada. Os encontros foram realizados às terças e sextas às 8 h00.

- Tarefa (ou Aplicação) - este é o componente mais importante de todos, e consiste na oportunidade de aplicar aquilo que foi aprendido nos dois momentos anteriores. A tarefa consiste de atividades (assíncronas) que deveriam ser completadas após cada encontro, em que seriam necessários os conhecimentos e habilidades apresentados e discutidos previamente, sempre com uma participação e avaliação formativa (feedback) dos pares e dos facilitadores.

- Plantão - consistiu em webconferências (síncronas) com 60 minutos de duração, com a finalidade de esclarecer dúvidas a respeito das tarefas ou de caráter mais geral. Os plantões foram realizados às segundas e quintas às $13 \mathrm{~h} 30$. 
Além dos elementos acima, foram também oferecidas sessões paralelas (ou sessões eletivas), que consistiram em webconferências (síncronas) opcionais com 60 minutos de duração, abordando temas adicionais: plano de ensino e aprendizagem (PEA), plataforma e-Aulas USP (http://eaulas.usp.br), e a ferramenta Questionário ativo do Moodle.

Para se garantir que cada estudante pudesse receber suporte e feedback mais individualizados e oportunos, planejou-se a divisão dos estudantes em grupos de 6 a 10, com um tutor para cada grupo, que ficaria encarregado de acompanhar mais de perto estes estudantes, esclarecendo dúvidas e auxiliando nas atividades.

Todas estas informações foram consolidadas em um plano de ensino e aprendizagem (PEA), que pode ser encontrado aqui (https://edisciplinas.usp.br/mod/folder/ view. php?id=3119880).

\section{DEVELOPMENT (DESENVOLVIMENTO)}

O desenvolvimento do curso foi baseado em dois pilares: (a) produção de material didático; e (b) seleção, inserção e configuração das atividades (tarefas, fóruns, questionários e outros) como estratégias de ensino e aprendizagem.

Para a produção de material didático, foram selecionados alguns textos de apoio, consistindo em leitura obrigatória e opcional; foram gravados tutoriais em vídeo, contemplando os principais aspectos, recursos e funcionalidades do eDisciplinas; e foram adaptados slides de outros cursos do CDDE com foco em boas práticas na docência. Para a gravação dos vídeos, foi utilizado o software Camtasia ${ }^{\circledR}$ :mac 2.10 .8 (TechSmith Corporation, Okemos, EUA), que foram posteriormente otimizados para streaming com o software HandBrake 1.2.0 (The HandBrake Team, https:// handbrake.fr/).

A plataforma dos cursos foi desenvolvida no e-Disciplinas, utilizando os recursos nativos do Moodle. Na $1^{a}$ edição, o design contava com muitas descrições dos itens na página inicial e organização dos módulos em botões clicáveis (círculos azuis) (Figura 2). Na 2a edição, após avaliação, foram feitas modificações no layout, reduzindo as descrições na página inicial, deixando o visual mais clean, e adotando-se a organização dos módulos em abas, o que permitia o uso de rótulos (Figura 3).

Adotou-se, em ambas as edições, a conclusão de atividades (pequenas caixas de seleção ao lado direito da tela) para que estudantes e professores pudessem acompanhar o progresso individual e coletivo. Destacamos o uso de rótulos com ícones para melhor identificar cada etapa de cada módulo (Preparo, Encontro, Tarefa e Plantão).

Além disso, cada estudante recebeu um ambiente de teste, "em branco", criados especificamente para o curso, onde pudessem praticar os novos conhecimentos e ferramentas em um ambiente seguro, sem o receio de interferir com os ambientes reais das disciplinas. Alguns participantes criaram seu AVA "do zero" e outros preferiram importar um dos seus cursos que já existiam para este espaço de teste e de aprendizagem e fizeram melhorias que foram depois disponibilizadas na forma de cursos reais aos estudantes no segundo semestre de 2020. Como foi comentado anteriormente esse é o espaço de criação e onde cada participante pode mostrar o que aprendeu e como fez uso deste conhecimento para criar seu próprio AVA. Como já foi mencionado, tanto os pares quanto os facilitadores acessavam esses ambientes como alunos para testar os recursos disponibilizados e dar devolutiva ao responsável por cada AVA.

\section{IMPLEMENTATION (IMPLEMENTAÇÃO)}

Foram oferecidas, na $1^{\text {a }}$ edição (14/07 a 10/08/2020), 60 vagas para docentes da FMRP e, na $2^{\text {a }}$ edição (08/09 a 05/10/2020), 50 vagas para docentes e pós-doutorandos da FMRP. Os cursos foram amplamente divulgados nas listas de e-mails institucionais e, no ato da inscrição, o candidato respondia a um breve questionário para determinar seu grau de familiaridade com o e-Disciplinas. Candidatos com perfil de baixa familiaridade eram direcionados ao e-MB.ini (para tutoria individualizada voltada para iniciantes), enquanto os demais eram direcionados ao e-MB.int.

$\mathrm{Na} 1^{\mathrm{a}}$ edição, tivemos 60 inscritos, dos quais $41(68 \%)$ concluíram satisfatoriamen- 
te o curso. Na $2^{a}$ edição, houve 43 inscritos, e $26(60 \%)$ concluíram o curso satisfatoriamente. Destacamos aqui o fato de que vários docentes inscritos no curso entraram em contato com os coordenadores, informando que, devido às suas grandes limitações de tempo, não seriam capazes de completar as tarefas necessárias para a conclusão oficial do curso, mas independentemente disso, continuaram participando das atividades síncronas, com grande proveito para eles.

\section{EVALUATION (AVALIAÇÃO DA EXPE- RIÊNCIA EDUCACIONẢL)}

Ao final de cada um dos oito módulos e ao final do curso, os estudantes eram convidados a preencherem um instrumento de avaliação no formato "Que bom, que pena, que tal?". Neste formulário o participante identifica o que gostou e gostaria que fosse mantido (Que bom); aquilo que não foi tão bom e que acredita que poderia ser melhorado (Que Pena) e as sugestões de meIhoria (Que Tal). No Quadro 2 apresentamos algumas das respostas obtidas de forma anônima. Resumidamente, os participantes elogiaram a iniciativa, destacaram o quanto participar do curso foi importante para seu aprimoramento como docente, e o quanto sabiam pouco sobre os recursos que tinham à disposição no e-Disciplinas. Destacaram também o aprendizado sobre aspectos pedagógicos que devem embasar o delineamento de um curso baseado em educação remota. Entre os fatores negativos mencionados, destacamos a falta de tempo maior para dedicação ao curso, um curso muito intensivo com excesso de atividades, e dificuldades de interação com os pares nas atividades em grupo. Entre as sugestões, destacam-se dar maior prazo para a conclusão das atividades, um curso mais extensivo, maior ênfase em métodos de avaliação, e realização de outros cursos com maior complexidade.

A metodologia ADDIE pressupõe que, após a fase de avaliação (evaluation), o ciclo recomece, preparando-se as próximas edições de um curso, incorporando o que foi aprendido e revisando ou excluindo o que não funcionou. Após recebermos as avaliações dos estudantes da primeira edição, juntamente com as percepções dos tutores, fi- zemos várias modificações na plataforma para a segunda edição do e-MB.int, entre as quais: redução do número de atividades em grupo, redução do número e da complexidade das tarefas, e instruções mais claras e detalhadas para sua execução, redução de informações na página principal (que ficou mais clean), redução do número de e-mails enviados, evitando assim sobrecarga das caixas de entrada (isto foi feito alterando as configurações dos Fóruns de Assinatura forçada para Assinatura opcional), e melhoria nas ferramentas de comunicação com os tutores e com os pares, reforçando o vínculo de cada grupo com seu tutor e criando um canal específico e privado para as comunicações (ferramenta Diálogo).

Ao final da $2^{a}$ edição, sentimos que as mudanças foram acertadas e melhoraram significativamente a experiência dos estudantes. Uma das atividades previstas nos dois cursos de modo intencional foi a solicitação de várias tarefas ao mesmo tempo para os participantes. Houve muitas reclamações, e isso permitiu que pudéssemos discutir um dos mais comuns erros que não professores cometemos quando elaboramos atividades tanto presenciais quanto a distância, sobrecarregar os estudantes e comprometer o engajamento e aproveitamento destes. Neste fórum, era possível refletir sobre objetivos de aprendizagem, aquilo que é interessante, importante e essencial. Quando priorizamos o essencial, o aproveitamento aumenta e a sobrecarga desnecessária diminui. De modo simples, devemos sempre ter em mente a máxima de que "menos é mais" na organização de atividades da educação remota ou a distância.

A seguir comentamos brevemente, as variações do e-MB.int que também oferecemos para atender um público com necessidades e perfis diversos.

\section{E-MÓDULO BÁSICO (INICIANTE) OU E-MB.INI}

Esta estratégia foi planejada para atender o docente com pouca ou nenhuma familiaridade com uso de tecnologias, AVAs ou a plataforma Moodle/ eDisciplinas. Para este grupo de docentes, propusemos um atendimento personalizado (um para um), em que o docente poderia manter encontros 
síncronos com seu tutor e realizar algumas atividades básicas e essenciais para o uso do e-Disciplinas. Contamos para isso com uma equipe de cinco tutores da equipe técnica administrativa da FMRP-USP e com experiência no Moodle. Assim, cada docente inscrito contaria com um tutor para treinamento síncrono individual, seguindo calendário e ritmo ajustados às necessidades de cada docente. O plano básico e objetivos de aprendizagem deste módulo incluía: criar o ambiente educacional no e-disciplina; oferecer conteúdo instrucional na forma de arquivos de texto, vídeos e links da internet; realizar comunicação síncrona e assíncrona com autonomia e segurança (síncrona - Google meet ou MConf, e assíncrona - Fórum do e-Disciplinas); propor atividades com intuito de promover aprendizagem (questionário nos formatos: Verdadeiro ou falso, múltipla escolha e ensaio (dissertativa); e corrigir tarefas e dar devolutiva (feedback) aos estudantes.

\section{E-MÓDULO BÁSICO (AVANÇADO) OU E-MB.AVAN}

Esta estratégia não foi muito utilizada, pois a maioria dos docentes da FMRP-USP encontrava-se na condição intermediária ou iniciante de conhecimento. Acreditamos que em 2021, os que fizeram o e-MB.int e praticaram nas suas disciplinas no segundo semestre terão dúvidas mais elaboradas que permitirão oferecermos alguns módulos mais avançados.

\section{E-MÓDULO BÁSICO (ESTUDO DIRIGI- DO) OU E-MB.ED}

Esta estratégia foi planejada para o docente que já tivesse alguma familiaridade com AVAs ou a plataforma Moodle/eDisciplinas, mas que não tivesse disponibilidade para participação em atividades síncronas; assim, todo o conteúdo e atividades foram disponibilizados de forma assíncrona, de forma que cada participante pudesse seguir seu próprio ritmo e calendário (self-paced course). A plataforma utilizada para este formato pode ser acessada livremente aqui: https:// edisciplinas.usp.br/course/view.php?id $=77804$ e aqui: https://cursosextensao.usp.br/course/ view.php?id $=1787$

Importante mencionarmos que o Instituto de Biociências da USP (Campus São Paulo) entrou em contato com o CDDE e com a coordenação do e-MB.int e uma versão customizada deste curso foi oferecida para dos docentes daquela Unidade da USP com a participação do Prof. Fabio Carmona. Essa foi uma atividade importante que de certa maneira validou o modelo e formato criado para a FMRP-USP em outra unidade, e outro contexto dentro da própria USP.

\section{CONSIDERAÇÕES FINAIS:}

A pandemia de COVID-19 trouxe desafios enormes para a educação que ainda não compreendemos totalmente e que não foram equacionados ainda nas instituições de ensino. No entanto trouxe também, forçosamente, uma oportunidade única para os docentes se familiarizarem e adquirirem competências relacionadas à educação remota e EaD. É responsabilidade institucional oferecer condições para o desenvolvimento docente e a partir das experiências e habilidades individuais do corpo docente, fomos capazes de criar um curso de capacitação docente para auxiliar nossos colegas e influenciar positivamente na qualidade da educação que seria oferecida na nossa Faculdade. Essas ações diminuíram bastante a lacuna existente entre o potencial oferecido pelos recursos disponibilizados pela USP através do e-Disciplinas e o pacote G-Suite e como cada professor da Universidade faz uso e tira o melhor destes recursos em um momento que a própria manutenção do ensino na Universidade esteve sob risco. Mais importante do que isto, uma rede de colaboração foi criada e se mantém ativa para apoio mútuo, laços foram estreitados e o senso de comunidade foi fortalecido.

\section{REFERÊNCIAS}

1. Brasil. Resposta nacional e internacional de enfrentamento ao novo coronavírus. Linha do tempo. [Internet]. Ministério da Saúde. 2020 [cited 2020 Dec 22]. Available from: https://coronavirus.saude.gov.br/index.php/ linha-do-tempo 
2. World Health Organization. Rolling updates on coronavirus disease (COVID-19). Events as they happen [Internet]. 2020 [cited 2020 Dec 22]. Available from: https:// www.who.int/emergencies/diseases/novel-coronavirus-2019/events-as-they-happen

3. São Paulo. Governo de SP determina quarentena em todo o Estado [Internet]. Últimas Notícias. 2020 [cited 2020 Dec 22]. Available from: https://www.saopaulo.sp.gov. br/ultimas-noticias/ao-vivo-governo-de-sp-anuncia-novas-medidas-para-combate-ao-coronavirus-no-estado/

4. Heitz C, Laboissiere M, Sanghvi S, Sarakatsannis J. Getting the next phase of remote learning right in higher education. McKinsey Co. 2020;(April).

5. Bates AW. Educar na Era Digital [Internet]. $1^{\text {a }}$. São Paulo: Artesanato Educacional; 2017. 607 p. Available from: http:// www.abed.org.br/arquivos/Educar na Era Digital.pdf 


\section{Quadros}

Quadro 1. Módulos e conteúdo resumido do curso e-Módulo Básico.

\begin{tabular}{|c|c|c|}
\hline Módulo & Tema & Conteúdo \\
\hline 1 & Introdução & $\begin{array}{l}\text { Futuro da educação médica; Educação remota e Ensino à distância; Característi- } \\
\text { cas do ensino de adultos; Comunicação efetiva e engajamento; Plano de ensino e } \\
\text { aprendizagem (PEA); Necessidade e técnica de feedback. }\end{array}$ \\
\hline 2 & Ambiente & $\begin{array}{l}\text { Características do ambiente educacional; Ambientes virtuais de aprendizagem } \\
\text { (AVAs); Criação e configurações de ambientes no eDisciplinas; Princípios de design } \\
\text { instrucional, layout e organização visual; Métodos de inscrição para docentes e } \\
\text { estudantes. }\end{array}$ \\
\hline 3 & Conteúdo & $\begin{array}{l}\text { Estratégias de ensino e aprendizagem; Material instrucional, tipos, características e } \\
\text { métodos de oferta: arquivo (texto, imagem, áudio, vídeo), pasta de arquivos, ende- } \\
\text { reço web e página. }\end{array}$ \\
\hline 4 & Comunicação & $\begin{array}{l}\text { Engajamento e interação com estudantes como estratégia de ensino e aprendiza- } \\
\text { gem; Pequenos grupos e peer-learning; Ferramentas de comunicação online: redes } \\
\text { sociais, chats, diálogos, fóruns e ferramentas de webconferência (Google Meet e } \\
\text { MConf }{ }^{1} \text { ). }\end{array}$ \\
\hline 5 & Atividades 1 & $\begin{array}{l}\text { Atividades para avaliação formativa; Ferramentas online para atividades formativas: } \\
\text { glossários, tarefas, questionários e fóruns. }\end{array}$ \\
\hline 6 & Atividades 2 & $\begin{array}{l}\text { Boas práticas para elaboração de questões: verdadeiro e falso, ensaio, múltipla } \\
\text { escolha e correlação; Tipos de questões mais comuns disponíveis no eDisciplinas: } \\
\text { descrição, verdadeiro e falso, múltipla escolha, dissertação, associação, arrastar e } \\
\text { soltar, cálculo; Organização de um banco de questões: categorias e tags. }\end{array}$ \\
\hline 7 & Avaliação 1 & $\begin{array}{l}\text { Avaliação somativa e formativa; Feedback como elemento central da avaliação; } \\
\text { Configuração de questionários para avaliação formativa e somativa no eDisciplinas; } \\
\text { Avaliação oral online. }\end{array}$ \\
\hline 8 & Avaliação 2 & $\begin{array}{l}\text { Avaliação de disciplinas e programas educacionais; Acompanhamento do progresso } \\
\text { de estudantes: conclusão de atividades, relatórios, checklists, listas de presença, } \\
\text { estatísticas e livro de notas; Ferramentas para coletar informações de avaliação da } \\
\text { disciplina pelos estudantes: enquete. }\end{array}$ \\
\hline
\end{tabular}

Legenda: 1, MConf (http://mconf.org) é uma ferramenta de código aberto para webconferências desenvolvido a partir do BigBlueButton (https://bigbluebutton.org), e adaptado para uso pela Rede Nacional de Ensino e Pesquisa (RNP, https://www.rnp.br), com apoio do Governo Federal, e integrada ao eDisciplinas (https://edisciplinas.usp.br). 
Quadro 2. Respostas (anônimas) dadas pelos estudantes (docentes e pós-doutorandos da FMRP-USP) aos instrumentos de avaliação do curso e-Módulo Básico (Intermediário).

Que bom... • - Tudo de bom! Didática dos professores, metodologia aplicada, material de ensino riquíssimo. Aulas gravadas muito instrutivas, curtas e objetivas. Todos professores maravilhosos. [...] Foi de grande valia. Com o material disponibilidade poderemos chegar lá. Obrigado de verdade!

- O curso nos deu segurança para construirmos os nossos ambientes virtuais de ensino e aprendizagem e, claro, trabalharmos come eles. Os pontos altos do curso foram as aulas (todas muito boas - curtas, claras e objetivas), as discussões (elucidativas e de alto nível) e disponibilidade dos preceptores. Parabéns!

- As reflexões sobre aspectos pedagógicos. As discussões sobre os modos e validade da avaliação. Os tutoriais sobre o uso das ferramentas para avaliação e medida de desempenho individual e da classe no eDisciplinas (já conhecia e usava muitos deles, mas aprendi bastante sobre detalhes de como configurar e essa foi a parte mais importante nesse quesito). Os desafios de gravar vídeos e gerar os ambientes da disciplina. Os desafios de avaliar o ambiente de disciplinas dos colegas e com isso compreender as dificuldades associadas a encontrar e compreender informações dentro de um ambiente virtual. Receber avaliação do professor e dos colegas sobre meu vídeo e sobre meu ambiente de disciplina. O fórum de discussão da semana foi muito pertinente a medida que explicita um problema real da educação à distância a ser enfrentado e resolvido. A questão da integridade vs privacidade na avaliação é muito séria e devemos ter uma resposta para lidar com isso.

- Achei o curso todo muito bom, superou minhas expectativas, de novo. Adorei as discussões, que se tornaram progressivamente mais ricas conforme as semanas se passaram. Gostei muito de como os docentes responsáveis se organizaram, cada um cuidando de um pedacinho e, ao mesmo tempo, todos sabendo de tudo. Uma atenção especial aos auxiliares de TI, que sempre estiveram atentos e prontos para ajudar. Gostei também que a parte mais técnica ficou para a tarefa, com os vídeos. A parte importante ficou para o presencial.

- Gostaria de agradecer imensamente a oportunidade que me foi dada de fazer este curso. Eu já tinha alguma familiaridade com o uso do Moodle e sabia da subutilização que fazia, mas não tinha ideia de que haviam tantas mais ferramentas à minha disposição. Foi muito produtivo, um formato "hands on" que permitiu claramente que puséssemos em prática estas ferramentas, tivéssemos dúvidas e uma incansável disponibilidade de todos os envolvidos em nos ajudar (agradeço aqui os docentes e a equipe não-docente da TI que foi fenomenal). Pretendo aplicar o que aprendi na minha disciplina de pós-graduação neste segundo semestre. O meu ambiente de teste da disciplina foi importado da disciplina real, mas acrescentei vários recursos e atividades que pretendo exportar quando da montagem da disciplina de 2021. Além disso, pretendo incluir várias atividades interativas antes não existentes no corpo da disciplina. Mais uma vez o meu MUITO OBRIGADA!

- As apresentações de novas metodologias de ensino remoto/EAD, os vídeos gravados com instruções para uso da plataforma e as discussões sobre formas de avaliação.

- Foi ótimo ter participado do curso. Desde o início estava ansiosa aguardando pelo aprendizado de ferramentas úteis para elaborar formulários de avaliação da disciplina, que aprendemos esta semana. As atividades síncronas da semana foram ótimas! Parabéns a todo corpo docente!

- Eu adorei fazer parte deste curso!! Achei muito legal aprender várias ferramentas disponíveis no Moodle!! Excelente recurso para as aulas tanto a distância, quanto presenciais! Todos os tutores foram muito atenciosos e dispostos a nos ajudar a melhorar sempre! As vídeo aulas [...] são de grande ajuda! Assim sempre que for necessário incluir algo no ambiente real, podemos conferir os passos daquela atividade. Os plantões de dúvida foram essenciais para o desenrolar do Moodle. Adorei conhecer o recurso Lição! Depois quero aprender a fazer!

- Que bom que consegui aprender e aprofundar várias questões sobre o processo de educação. Muito obrigada.

- O curso como um todo foi excelente! Todos os conteúdos abordados e as discussões foram muito ricas e acredito que tenham permitido o entendimento teórico e prático em vários aspectos. Os exercícios propostos foram muito úteis para realmente nos ensinar a utilizar a plataforma do eDisciplinas. E as discussões alcançaram não apenas aquilo que era proposto como atividade, mas também na auto-avaliação como docente, o papel que cada um desempenha e o valor que se traz em tudo o que fazemos. Foi mais uma vez uma oportunidade de crescimento profissional e pessoal. Parabéns a todos os envolvidos no curso!

- Muito bom o curso. Obrigado por este momento de aprendizado. Fez a diferença na minha vida profissional. 


\section{Quadro 2}

(continuação)

Que pena... - $\quad$ Tempo curto. Muitas tarefas para desempenhar em curto tempo. O tempo deveria ser maior lamento minha pouca disponibilidade de tempo por excesso de atividades.

- As informações dos vídeos pareciam simples, mas sua execução demandou bastante tempo.

- Excesso de tarefas. No meu caso em particular, estava com as atividades acadêmicas a pleno vapor - fora as nossas atividades do dia a dia. Não consegui participar de nenhum plantão de dúvidas (apesar de várias) e quase não consigo terminar em tempo as tarefas. Quero deixar claro que todas as tarefas foram muito interessantes, didáticas e essenciais para o aprendizado. Mas, realmente, a falta de tempo atrapalhou bastante.

- No meu caso, em especial, tive algumas variáveis que não foram muito "favoráveis": o horário de realização dos encontros síncronos acabou sendo um pouco mais complicado com duas crianças em casa; eu particularmente estava passando por um período muito desgastante [...], então acredito que um encontro por semana e um período mais longo de curso poderia ter me auxiliado a seguir com mais assiduidade nas atividades.

- Muitas atividades extras. Isto pode gerar um pouco de ansiedade. Aumenta a preocupação em cumprir as tarefas e pode comprometer a sua qualidade.

- Não consegui fazer as atividades do curso.

- Que pena que não pude me dedicar o quanto gostaria ao curso.

- $\quad$ Em relação à semana, não consegui receber nenhum convite para poder avaliar o ambiente virtual ou a atividade de questionário de outro participante. Gostaria de ter podido ter essa experiência. Em relação ao curso, acho que poderíamos treinar nas aulas síncronas mais algumas atividades, como foi feito com a prova online que fizemos. Acho que se ao longo do curso conseguíssemos fazer algumas atividades junto do professor, no momento da aula, poderia levar à algumas discussões ou dúvidas que às vezes aparecem nas tarefas (que fazemos em outros momentos), e que por vezes acabamos esquecendo de comentar nos plantões ou aulas síncronas posteriores. 
Quadro 2

(continuação)

Que tal...? - Q Que tal dar mais prazo para a atividade de conclusão?

- Aulas semanais, para dar tempo para aqueles com mais dificuldades conseguirem acompanhar o curso melhor

- Fazer o curso em seis semanas diluindo as tarefas ao longo desse período.

- A última aula, na última sessão, poderia ter esclarecido melhor quanto aos métodos de avaliação de uma disciplina e os modelos que se quer adotar na FMRP. A última semana e sessão final poderia, também, ter aberto para uma reflexão sobre os riscos que a padronização do ensino universitário pode trazer à formação, uma vez que ela pode reduzir a criatividade e autonomia para o ensino e aprendizado. Não podemos nos esquecer que a FMRP floresceu e deu frutos reconhecidos mundialmente sem ter adotado regras muito 'padronizadas e facilitadas' de ensino. Quero dizer o seguinte, até que ponto o ensino baseado em questionários (testes, quizzes, enquetes) e outras facilitações não reduzem o estímulo para uma leitura aprofundada e a aquisição do conhecimento por meio do estudo teórico-reflexivo?

- Oferecer outros cursos, com conteúdos complementares e de complexidade crescente com mais tempo para a realização das atividades.

- Que tal fazer sessões paralelas para discutir temas específicos sobre o processo de ensino -aprendizado? Senti que embora as discussões durante os encontros fossem riquíssimas, foram abreviadas pelo tempo limitado.

- A FMRP deveria criar uma norma/orientação de que novos docentes façam cursos do CDDE (ao menos o Modulo Básico) durante os anos iniciais da carreira docente (talvez durante o probatório).

- Na verdade, esta semana foi a que mais aproveitei o curso. Acho que entendi que, em tempo, que as discussões das segundas e quintas são tão importantes quanto as aulas das manhãs.

- Manter o curso aberto após seu fim para que possamos ter acesso ao conteúdo. Curso complementar ou de nível mais avançado para o ensino de ferramentas que não foram possíveis ser mostradas.

- Eu achei ótimo, mas talvez eu adicionasse um módulo de como o docente pode gerenciar as respostas dos alunos, exportar conteúdo para planilhas externas para fazer uma análise extra...

- $\quad$ Fazer um fechamento de como inserir e avaliar a utilização da rubrica na atividade de avaliação por pares.

- Talvez uma pequena redução na carga horária possa permitir um tempo maior para que os docentes possam assimilar melhor todo o conteúdo.

- Acho que colocaria uma aula presencial de como avaliar o nível de dificuldade de prova e questão.

- Ter a opção de um curso com maior intervalo entre as aulas, para ter tempo de rever a aula e concluir as tarefas.

- Que tal adicionar uma semana a mais no curso para testarmos a plataforma de forma síncrona, nas aulas? Seria como uma conclusão do curso, como uma simulação de um ambiente de aula online ao vivo. E até mesmo apresentar alguns problemas que podem vir a acontecer e pedir para que a gente lance possíveis soluções para o problema.

- Deixar um "canal" aberto para tirar dúvidas que apareçam no futuro, montando nossas disciplinas no Moodle.

- Realizar capacitações sobre avaliação formativa abertas a docentes de todo o Brasil, levando o modo de pensar deste curso para outros ambientes acadêmicos. 
Figuras

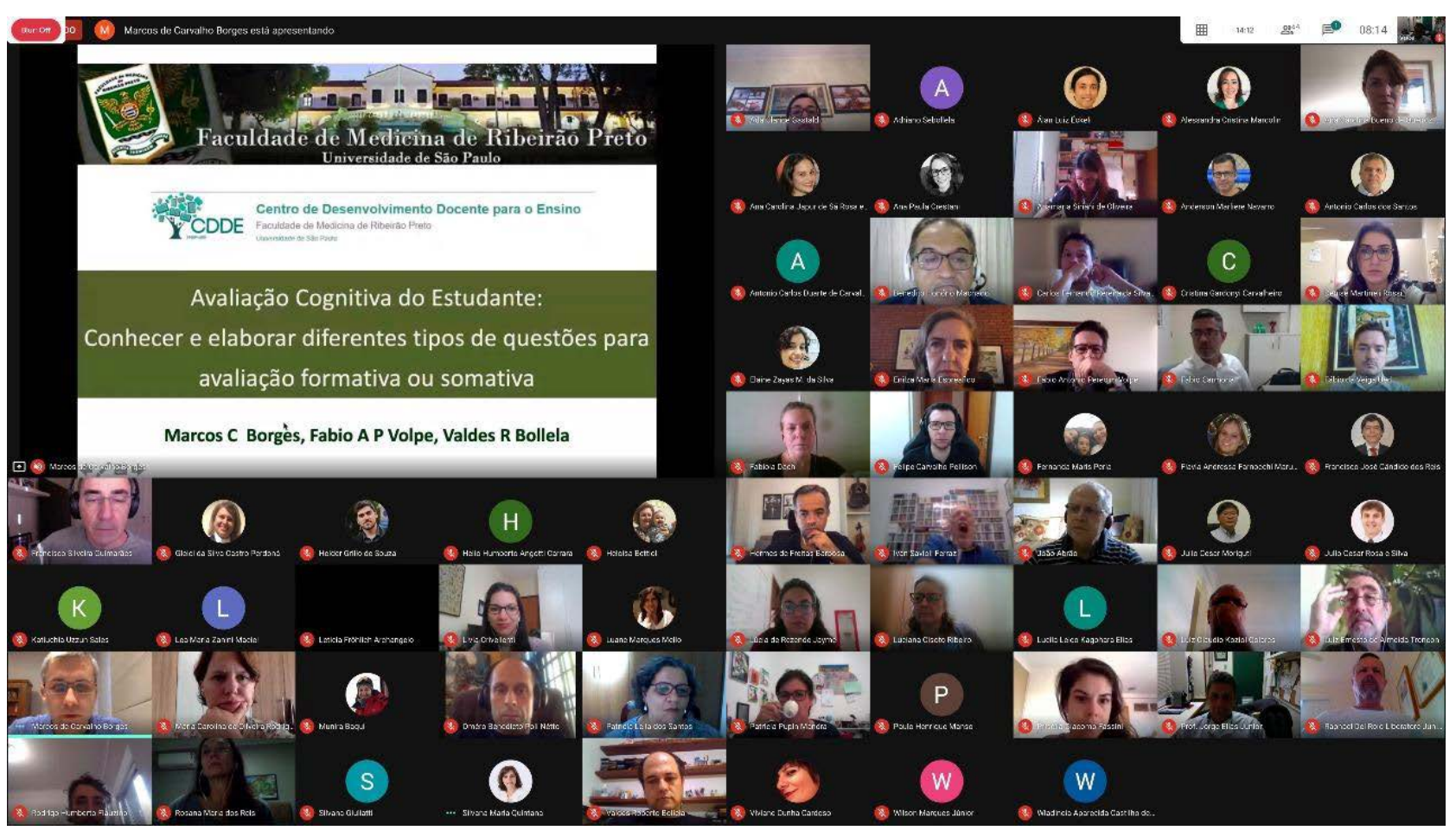

Figura 1. Screenshot do Encontro n. ${ }^{\circ} 6$ do e-Módulo Básico (Intermediário), $2^{\mathrm{a}}$ edição, com 64 participantes. 


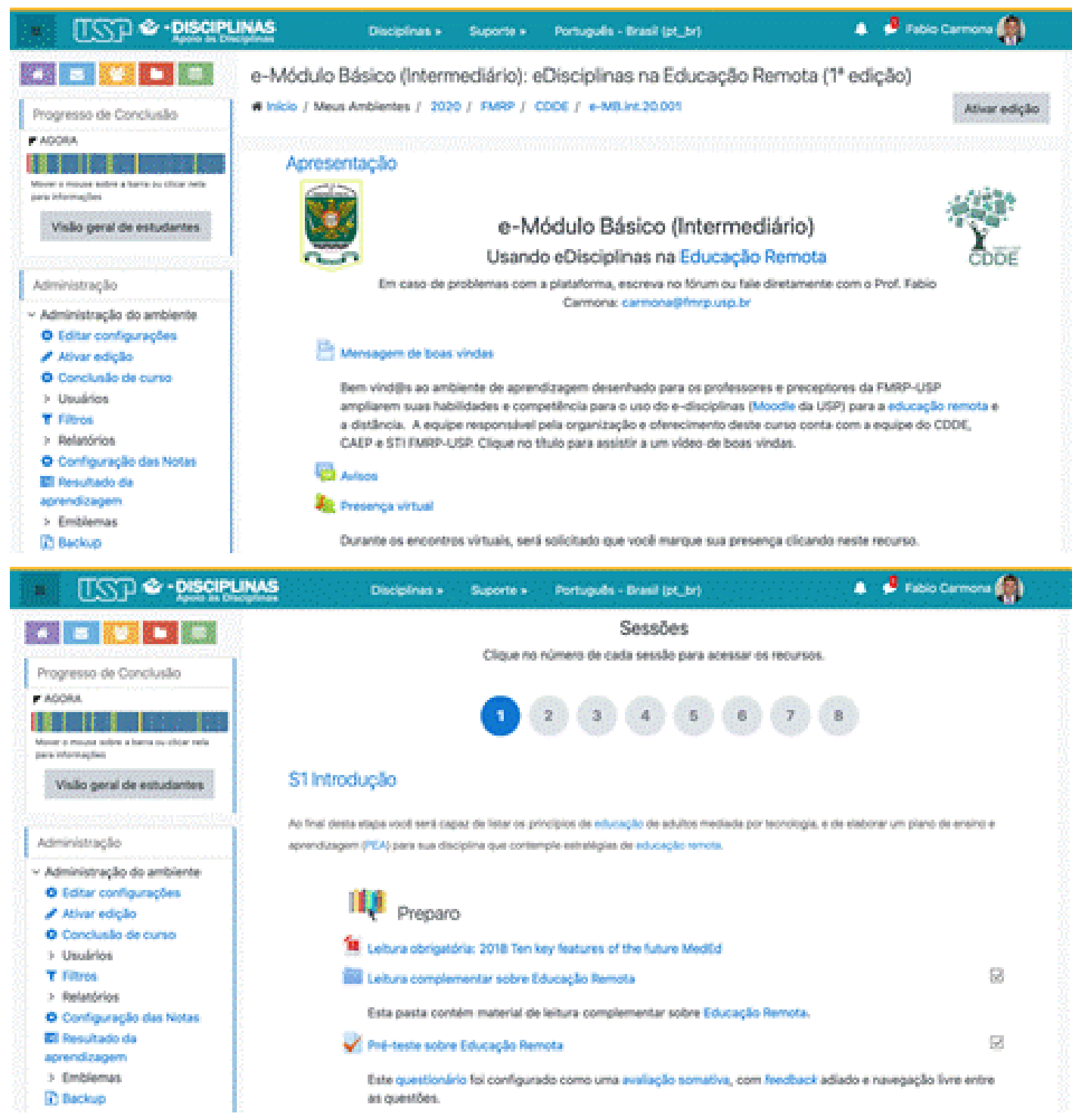

Figura 2. Screenshots da página inicial da plataforma do e-Módulo Básico (Intermediário), $1^{a}$ edição, no eDisciplinas. 


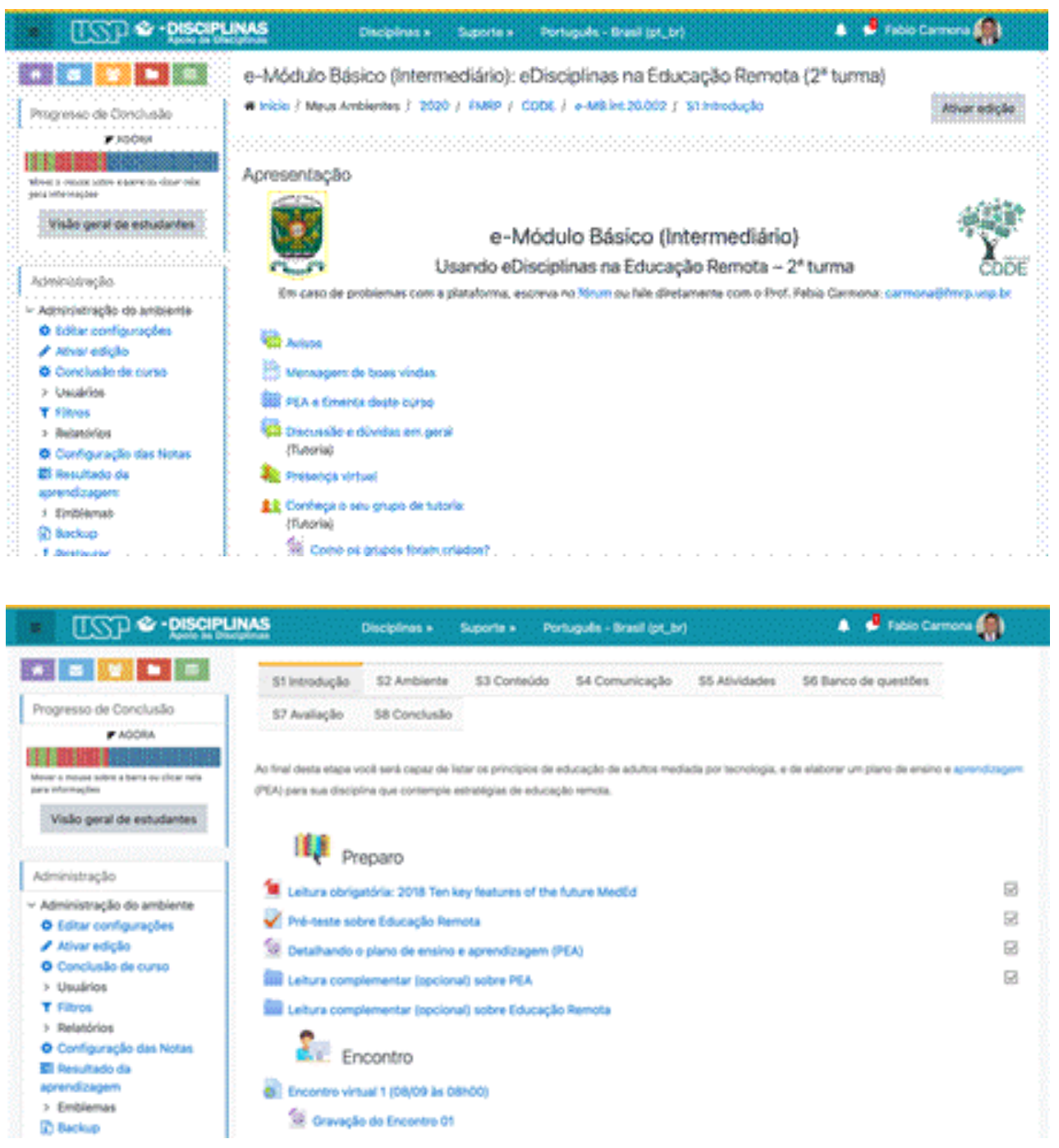

Figura 3. Screenshots da página inicial da plataforma do e-Módulo Básico (Intermediário), 2ª edição, no eDisciplinas. 


\section{Agradecimentos:}

Nossos mais sinceros agradecimentos a todos as pessoas envolvidas na viabilização dos cursos de capacitação que são objeto deste artigo: Aline Epiphanio Wolf (Departamento de Ciências da Saúde); Anamaria Siriani de Oliveira (Departamento de Ciências da Saúde); Anderson Marlieri Navarro (Departamento de Ciências da Saúde); Carlos Alberto Siqueira Lima Junior (Departamento de Puericultura e Pediatria); Fabio Antonio Perecim Volpe (Divisão de Cirurgia Pediátrica do HC); Fausto Bruno dos Reis Almeida (Departamento de Bioquímica e Imunologia); Felipe Carvalho Pellison (Seção Técnica de Informática); Francisco José Candido dos Reis (Departamento de Ginecologia e Obstetrícia); Helder Grillo de Souza (Departamento de Clínica Médica); Jorge Elias Junior (Departamento de Imagens Médicas, Hematologia e Oncologia Clínica); Lúcia de Rezende Jayme (Diretoria - CDDE/CRInt); Luiz Claudio Koziol Colares (Departamento de Puericultura e Pediatria); Luiz Ernesto de Almeida Troncon (Departamento de Clínica Médica); Marcos de Carvalho Borges (Departamento de Clínica Médica); Margaret de Castro (Departamento de Clínica Médica); Maria Paula Panuncio Pinto (Departamento de Ciências da Saúde); Rodrigo Humberto Flauzino (CAEP); Silvana Maria Quintana (Departamento de Ginecologia e Obstetrícia) e Wladineia Ap Castilho de Oliveira (Diretoria - CDDE).

\section{Contribuições:}

FC participou da idealização do manuscrito, escreveu a versão preliminar, revisou e aprovou a versão final, e assume responsabilidade pela exatidão e integridade de quaisquer partes do artigo. VRB participou da idealização do manuscrito, revisou e aprovou a versão final, e assume responsabilidade pela exatidão e integridade de quaisquer partes do artigo.

Financiamento:

Este trabalho não recebeu financiamento.

Editor:

Prof. Dr. Marcelo Riberto

Recebido: $11 / 05 / 2021$

Aprovado: $13 / 07 / 2021$ (c) (i) Este é um artigo publicado em acesso aberto (Open Access) sob a licença Creative sem restricões, desde que o trabalho original seja corretamente citado. 